\title{
Probing the Lewis Acid Catalyzed Acyclic Pathway of Carbohydrate Conversion in Methanol by In Situ NMR
}

\author{
Jensen, Pernille Rose; Taarning, Esben; Meier, Sebastian
}

Published in:

ChemCatChem

Link to article, DOI:

$10.1002 /$ cctc. 201901241

Publication date:

2019

Document Version

Peer reviewed version

Link back to DTU Orbit

Citation $(A P A)$ :

Jensen, P. R., Taarning, E., \& Meier, S. (2019). Probing the Lewis Acid Catalyzed Acyclic Pathway of Carbohydrate Conversion in Methanol by In Situ NMR. ChemCatChem, 11(20), 5077-5084.

https://doi.org/10.1002/cctc.201901241

\section{General rights}

Copyright and moral rights for the publications made accessible in the public portal are retained by the authors and/or other copyright owners and it is a condition of accessing publications that users recognise and abide by the legal requirements associated with these rights.

- Users may download and print one copy of any publication from the public portal for the purpose of private study or research.

- You may not further distribute the material or use it for any profit-making activity or commercial gain

- You may freely distribute the URL identifying the publication in the public portal 


\title{
Probing the Lewis Acid Catalyzed Acyclic Pathway of Carbohydrate Conversion in Methanol by In Situ NMR
}

\author{
Pernille Rose Jensen, ${ }^{[b]}$ Esben Taarning, ${ }^{[c]}$ and Sebastian Meier ${ }^{*[a]}$
}

\begin{abstract}
Future bioindustries will rely on the formation of diverse chemicals at high yield through various reaction pathways. These pathways include reactions to a series of alpha-hydroxy esters and acids that can be formed from the conversion of C3-C6 carbohydrates by Lewis acidic catalysts in alcohols and water. Definitive kinetic and mechanistic insights to support the development of carbohydrate conversion processes are arguably less developed than for analogous biocatalytic processes. Here, we visualize acyclic pathways of carbohydrate dehydration, using the acyclic C4 carbohydrate erythrulose as a probe molecule for the conversion by homogeneous $\mathrm{SnCl}_{4}$ in methanol. In situ studies allow the detection of previously postulated intermediates, identify the branch point to competing products and provide energetic and mechanistic insight by kinetic analysis. Reversibility of reactions, stereoselectivity and differential propensity for deuterium incorporation in competing pathways can be tracked by the formation of compounds with asymmetric mass distribution.
\end{abstract}

\section{Introduction}

A rising demand to accelerate the discovery and development of sustainable processes for biomass conversion to chemicals and fuels (materials and energy) is widely appreciated. Such developments hinge on the rapid and reliable quantification of potentially valuable products by suitable assays. In order to increase the future chances for success of sustainable processes, additional bottom-up approaches should prove valuable for evaluating catalyst function and robustness as well products formation, composition and value. Accordingly, high-resolution spectroscopic methods (especially NMR spectroscopy) have been increasingly applied to follow the progress of biomassconversion reactions. ${ }^{[1]}$ Arguably, such studies have been more widely applied in the study of lignin conversion ${ }^{[2]}$ than in the carbohydrate field. Mechanistic and kinetic studies of chemocatalytic carbohydrate conversion processes thus also lag behind the widely used analogous metabolic studies of biocatalytic carbohydrate conversion. ${ }^{[3]}$ As a consequence,

[a] Dr. S. Meier,

Department of Chemistry

Technical University of Denmark

Kemitorvet, Bygning 207, 2800 Kgs. Lyngby, Denmark

E-mail: semei@kemi.dtu.dk

[b] Dr. P.R. Jensen

Department of Health Technology

Technical University of Denmark

Elektrovej 349 2800-Kgs. Lyngby, Denmark

[c] Dr. E. Taarning

Haldor Topsøe A/S

Haldor Topsøes Allé 1, 2800-Kgs. Lyngby, Denmark

Supporting information for this article is given via a link at the end of the document. means to obtain definitive kinetic and mechanistic insights to support the development of carbohydrate conversion are arguably not used to their full potential. ${ }^{[4]}$

As the abundant pentose and hexose carbohydrates can occur in various cyclic and acyclic forms, corresponding cyclic or open-chain pathways can play a role in the formation of carbohydrate-derived chemicals. ${ }^{[5]}$ The difficulties in obtaining definitive insight into carbohydrate conversion processes are consequently well witnessed by the long-standing debate on the role of cyclic and acyclic routes of carbohydrate conversion to furanic compounds, ${ }^{[1 a, 6]}$ which are widely investigated as future precursors for instance of polymers, pharmaceuticals, fuel additives and solvents. Acyclic routes are likely central in the formation of alpha-hydroxy esters and acids by Lewis acidic catalysts in alcohols and water. Alpha-hydroxy esters bear promise as bio-derived solvents and polymer building blocks. While the C3-metabolite lactate can be obtained in attractive yields from chemocatalytic approaches as well, ${ }^{[7]}$ non-metabolite C4- to C6-alpha-hydroxy esters are more difficult to obtain, with decreasing maximum yields from $\mathrm{C} 4$ to $\mathrm{C} 6 .^{[5 a, 5 b, 8]}$ These C4- to C6-alpha-hydroxy esters contain ample functionality to make them prospective substrates for several higher-value chemicals. ${ }^{\left[{ }^{[9}\right.}$ The C4 variants thus are most promising targets that are not abundantly formed by biocatalysis. Tetrose carbohydrate substrates are rather rare and expensive, but recent approaches have shown the selective accessibility of tetroses from aldol condensation reactions from glycolaldehyde ${ }^{[10]}$ or $\mathrm{C} 3+\mathrm{C} 1$ fragments $^{[11]}$ and from retro-aldol cleavage reactions of C6 sugars. ${ }^{[12]}$ Likewise, C4 alpha-hydroxy esters can be formed directly in situ from larger and smaller than C4 sugars. ${ }^{\text {[a, } 10,11 b, 13]}$ Thus, C4 alpha-hydroxy esters constitute major byproducts in the formation of methyl lactate from hexoses and from disaccharides, ${ }^{[7 a, 10]}$ and major products in the conversion of glycolaldehyde by Lewis acidic catalysts enabling $\mathrm{C}-\mathrm{C}$ bond formation. ${ }^{[1 \mathrm{~b}, 8,10,13 \mathrm{a}]}$

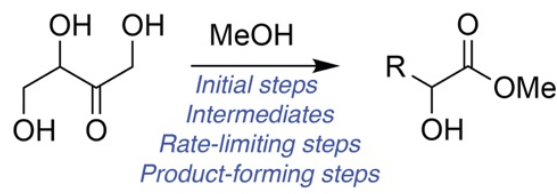

Scheme 1. Details of the acyclic pathway of sugar conversion that were experimentally explored using erythrulose as the probe for conversion by $\mathrm{SnCl}_{4}$ in short-chain alcohol.

Beyond their prospective roles as substrates for bio-derived polyesters and solvents, tetroses are attractive substrates to study the acyclic pathways of carbohydrate conversion. ${ }^{[1 b]}$ Tetroses are long enough to enable various intramolecular isomerization, dehydration, cyclization and acetalization reactions, while having high acyclic populations. The ketotetrose erythrulose is an acyclic carbohydrate that cannot form stable cyclic 
conformers. Hence, erythrulose is an obvious probe molecule for studying the Lewis acid catalysed reactions in methanol through reaction progress monitoring. High-field NMR, hyperpolarization and isotope exchange studies were combined to visualize and characterize the acyclic pathway of carbohydrate conversion and to obtain definitive answers on previously hypothesized mechanisms (Scheme 1). Specifically, we sought to obtain (1) insight into the early, rate-limiting and elusive steps of carbohydrate conversion, (2) detection, structural assignment and comprehensive set of ${ }^{13} \mathrm{C}$ NMR chemical shift assignments for intermediates, byproducts and products of the acyclic pathway, (3) detailed kinetic scrutiny of the rate limiting steps in the pathway from quantitative high-field in situ NMR on reaction progress, and (4) insight into the final, product-forming steps from kinetic isotope effects and distinction of molecules with differing isotope distributions.

\section{Results and Discussion}

Hyperpolarized NMR recognizes branching reaction from an elusive 1-oxo-2,3-enol species

A means to gain insight into initial steps of carbohydrate conversion consists in the temporary redistribution of ${ }^{13} \mathrm{C}$ nuclear spin states to obtain a transient enhancement of the NMR signal by four orders of magnitude. ${ }^{[14]}$ This process is called nuclear spin hyperpolarization and employs the transfer of magnetization from electrons to nuclei at low temperature prior to rapidly bringing the sample to a state that is suitable for liquid state NMR observation. The temporary enhancement of the NMR signal fades with an exponential decay of characteristic decay time on the seconds to minute time scale for non-protonated carbon sites. The vast NMR signal enhancement allows reaction tracking with sub-second to second time resolution. Hence, fast, initial conversions especially at or near the quaternary C2-position in erythrulose could be addressed using this approach (Scheme 2) even at natural isotope abundance, where only $1 \%$ of the erythrulose $\mathrm{C} 2$-sites carry the NMR detectable ${ }^{13} \mathrm{C}$ isotope.

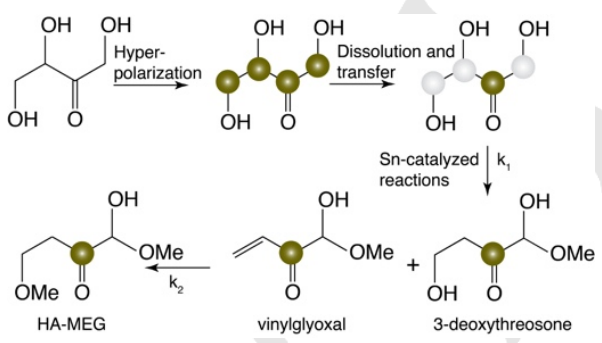

Scheme 2. Schematic depiction of the use of erythrulose at natural isotopic abundance to detect early reactions in the the $\mathrm{SnCl}_{4}$-catalyzed conversion upon nuclear spin hyperpolarization. Hyperpolarization temporarily enhances the signal of the carbon backbone (solid spheres). Protonated sites largely lose the hyperpolarization during transfer (light grey spheres), while the chemistry of the enhanced quaternary $\mathrm{C} 2$ signal is tracked.

The resultant experimental data are displayed in Figure 1 as a time series of ${ }^{13} \mathrm{C}$ NMR spectra. Reaction intermediates that were formed from erythrulose by $\mathrm{SnCl}_{4}$ in methanol became observable within few seconds of experiment time. Most notably, elusive 3deoxythreosone and vinylglyoxal species could be observed as the first intermediates accumulating to significant amounts in the reaction. The 3-deoxythreosone and vinylglyoxal emerged in parallel, which strongly indicated that both molecules are formed from a common precursor in competing (parallel) reactions. The precursor can presumably either be dehydrated to form vinyloglyoxal or tautomerize to 3-deoxythreosone. The most plausible precursor form thus validates the previously hypothesized role of a 1-oxo-2,3-enol species as the branch point in the acyclic route of Lewis acid catalyzed carbohydrate
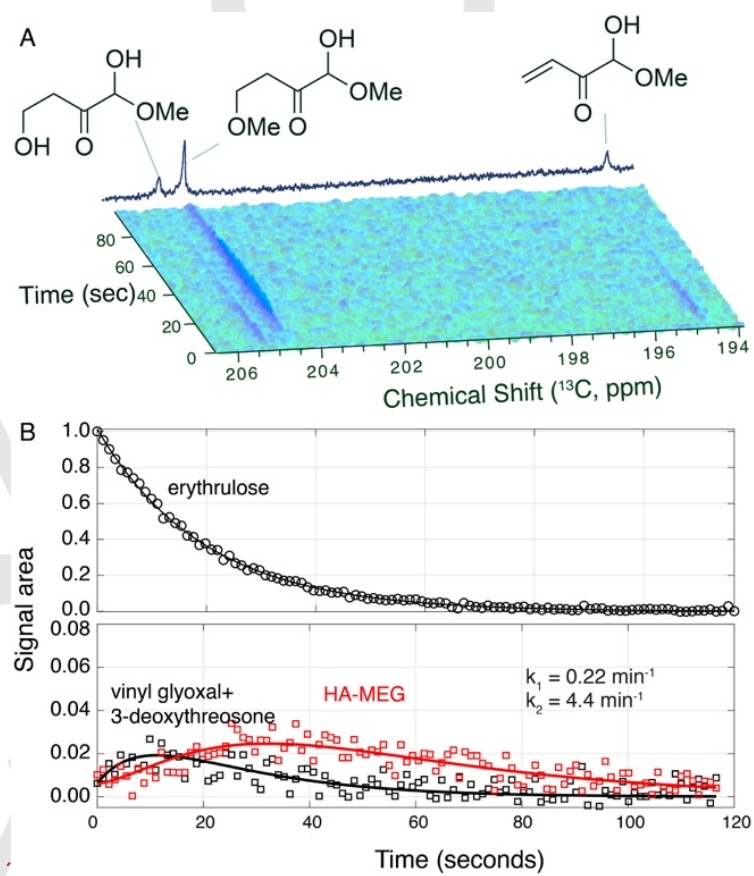

Figure 1. Times series of molecular species detected from hyperpolarized erythrulose with $\mathrm{SnCl}_{4} /$ methanol at $313 \mathrm{~K}$ and natural isotopic abundance. Due to the rapid fading of signal from protonated sites, all detected signals arise from the $\mathrm{C} 2$ position. The rate constants $\mathrm{k}_{1}$ and $\mathrm{k}_{2}$ are as defined in Scheme 2.

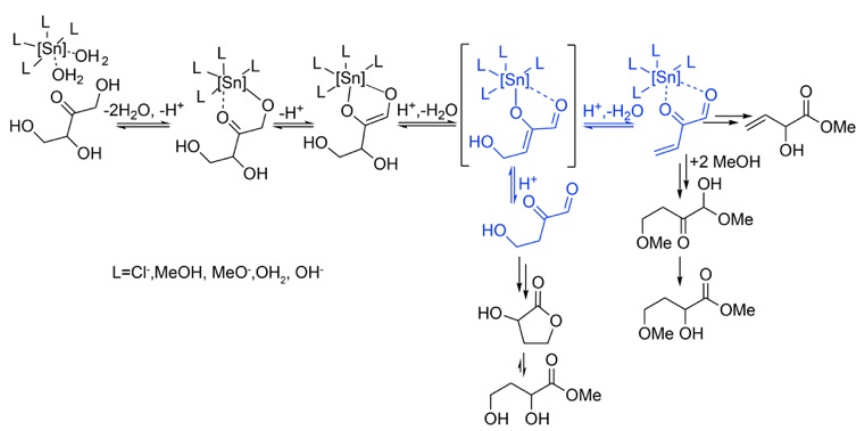

Scheme 3. Reaction scheme highlighting the formation of 3-deoxythreosone and vinylglyoxal from a common elusive precursor (blue, displayed in a bracket). Partial hydrolysis of $\mathrm{SnCl}_{4}$ to active species may occur, as indicated. ${ }^{[15]}$ 
conversion (Scheme 3). In methanol at mild reaction conditions, both pathways showed comparable influx as witnessed by comparable signals of vinyloglyoxal and 3-deoxythreosone species.

\section{Identification and chemical shift assignment of reactants}

The three rapidly formed molecules displayed in Figure 1 carry characteristic ${ }^{13} \mathrm{C} 2$ chemical shifts of carbonyl groups adjacent to a 3-deoxy position and an aldehyde ( $205 \mathrm{ppm})$ and a carbonyl group adjacent to a vinyl and an aldehyde group ( 195 ppm), respectively. The full molecular structures were determined by acquiring two-dimensional assignment spectra on reaction media at $293 \mathrm{~K}$, which slowed reactions sufficiently down to permit the detection of molecules that were formed from erythrulose by $\mathrm{SnCl}_{4}$ catalysis in methanol. Such in situ 2D NMR verified that the carbonyl signal at $194.7 \mathrm{ppm}$ is adjacent to a vinyl group and thus corresponds to vinyl glyoxal. Similarly, the signal at $205.5 \mathrm{ppm}$ was adjacent to a methylene group, followed by a primary alcohol in 3-deoxythreosone. Hence, in situ 2D NMR on stabilized samples validates the assignments shown above (Figures S2-S4). A comprehensive list of $\mathrm{C} 4$ species and their corresponding ${ }^{13} \mathrm{C}$ NMR chemical shift assignments determined in this way is shown in Figure 2.<smiles>C=CC(=O)C(OC)OC(=O)C(O)C(O)C(O)CO</smiles>

vinylglyoxal<smiles></smiles>

HA-MEG<smiles>COC(=O)C1CCCCC1C(=O)O</smiles>
$\mathrm{OMe} \mathrm{OH}$ MMHB

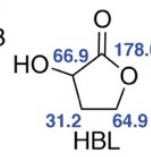<smiles>C=CC(O)C(=O)OC(=O)CC(O)CC(=O)C(OC)OC</smiles>

DMA-MEG

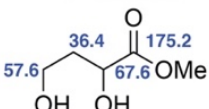

Figure 2. Overview of ${ }^{13} \mathrm{C}$ chemical shift assignments of compounds identified in a stabilized reaction mixture at $293 \mathrm{~K}$ with methanol- $\mathrm{d}_{4}$ as the solvent.

\section{Real time NMR of the acyclic pathway at different temperatures}

The comprehensive ${ }^{13} \mathrm{C}$ chemical shift assignments of Figure 2 were subsequently validated by identical amounts and kinetic profiles in in situ NMR experiments. These experiments were used to follow the overall reaction progress beyond the initial branching point that was identified with hyperpolarized NMR. High-field NMR on an $800 \mathrm{MHz}$ instrument equipped with cryogenically cooled detection electronics was used to obtain time series of ${ }^{13} \mathrm{C}$ NMR spectra. The ${ }^{13} \mathrm{C}$ NMR signal sensitivity provided by the above system allows the acquisition of ${ }^{13} \mathrm{C}$ NMR spectra with good time resolution of approximately 5 minutes per spectrum (Figure 3). The ${ }^{13} \mathrm{C}$ NMR spectra employed inversegated decoupling only during data acquisition in order to avoid enhancement of protonated sites. Reactions were conducted using stock solutions of reactants to warrant reproducibility when performing reaction kinetic analyses at 293,313 , and $333 \mathrm{~K}$. Integrals of the $\mathrm{C} 4$ positions with the lowest ${ }^{13} \mathrm{C} \mathrm{T}_{1}$ relaxation times $^{[16]}$ were used for obtaining relative determinations of the main reactive species.

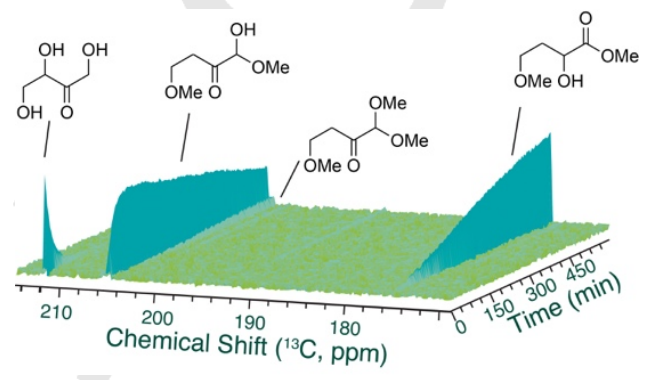

Figure 3. Time series of ${ }^{13} \mathrm{C}$ NMR spectra at $313 \mathrm{~K}$. Reaction conditions: $30 \mathrm{mg}$ erythrulose, $6 \mathrm{mg} \mathrm{SnCl}_{4} \cdot 5 \mathrm{H}_{2} \mathrm{O}, 600 \mu \mathrm{l}$ methanol- $\mathrm{d}_{4}$.

The time series of ${ }^{13} \mathrm{C}$ NMR spectra of reaction progress as shown in Figure 3 displayed that the overall reaction from erythrulose proceeded as a reaction with HA-MEG as the principal intermediate, which accumulates due to its slower conversion to the main product MMHB. The time series provided excellent sensitivity of the baseline-separated ${ }^{13} \mathrm{C}$ signals for reliable kinetic analyses of the main reactants. Signal areas in the time series were normalized to the methanol solvent signal to account for theoretically possible NMR instrument instabilities. The reaction of erythrulose was of first order with respect to the substrate concentration, so that substrate decay followed an exponential decay at all three temperatures (Figure 4 and S5). Owing to the low accumulation of other intermediates, the conversion of substrate and of HA-MEG clearly have the lowest rate constants in the acyclic pathway of erythrulose to MMHB. The reaction was therefore treated as a consecutive reaction of two elementary steps. The first of these steps corresponds to a net intramolecular redox reaction with oxidation of $\mathrm{C} 1$ and reduction of $\mathrm{C} 3$ under concomitant formation of a methyl ether at $\mathrm{C} 4$. The second step to $\mathrm{MMHB}$ in turn results in the further oxidation of $\mathrm{C} 1$ and reduction of $\mathrm{C} 2$. Byproducts include the furanoside acetals methyl-threoside and methy-erythroside in addition to the dimethyl acetal of the MEG intermediate. These findings underline that erythrulose can isomerize to some degree to its aldose tautomers ${ }^{[17]}$ under the current reaction conditions and that acetals form poorly-reactive, masked byproducts in the conversion of carbohydrates in alcohols (Figure S1). ${ }^{[18]}$ 


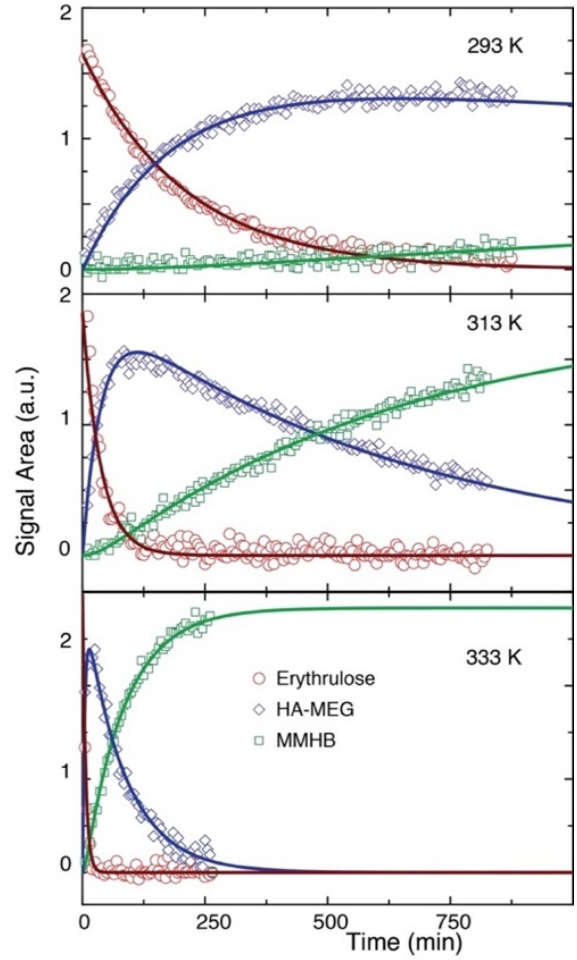

Figure 4. Integrated signal areas for the three main reactants at $293 \mathrm{~K}, 313 \mathrm{~K}$ and $333 \mathrm{~K}$. Areas are normalized to the solvent signal. Reaction conditions: 30 mg erythrulose, $6 \mathrm{mg} \mathrm{SnCl}{ }_{4} \cdot 5 \mathrm{H}_{2} \mathrm{O}, 600 \mu \mathrm{l}$ methanol- $\mathrm{d}_{4}$.

The signals of the substrate erythrulose and HA-MEG intermediate both approach zero and the conversions were treated as overall irreversible steps. Resultant fits of reaction progress curves to a consecutive two-step kinetic model are shown in Figure 4 and the obtained rate constants are plotted on a logarithmic scale versus the inverse absolute temperature for Arrhenius analysis in Figure 5. This analysis yields the apparent activation energies of the two main reaction steps converting erythrulose and HA-MEG. The linear trend in the Eyring analysis yielded estimates of activation enthalpies of $66 \mathrm{~kJ} / \mathrm{mol}$ for the conversion of erythrulose to HA-MEG and of $85 \mathrm{~kJ} / \mathrm{mol}$ for the subsequent conversion of HA-MEG to MMHB. These values are consistent with previous reports of the apparent activation energy for $\mathrm{SnCl}_{4}$-catalyzed conversion of erythrulose to MMHB (81 $\mathrm{kJ} / \mathrm{mol})^{[8]}$ and are plausible for reactions that progress during few hours in the temperature range that was investigated. The temperature-dependence of rate constants indicates that HAMEG formation remains the faster step than its conversion over a wide temperature range, which shows that HA-MEG will accumulate as a major intermediate under relevant operation conditions of the homogeneous catalytic system in methanol. Kinetic analysis of hyperpolarized and thermal NMR data in combination showed that the dehydration of erythrulose to vinylglyoxal was followed by approximately 20 -fold faster (to HA$M E G$ ) and 20-fold slower steps to the final product MMHB in the homogeneous reaction (Figure 5, bottom).

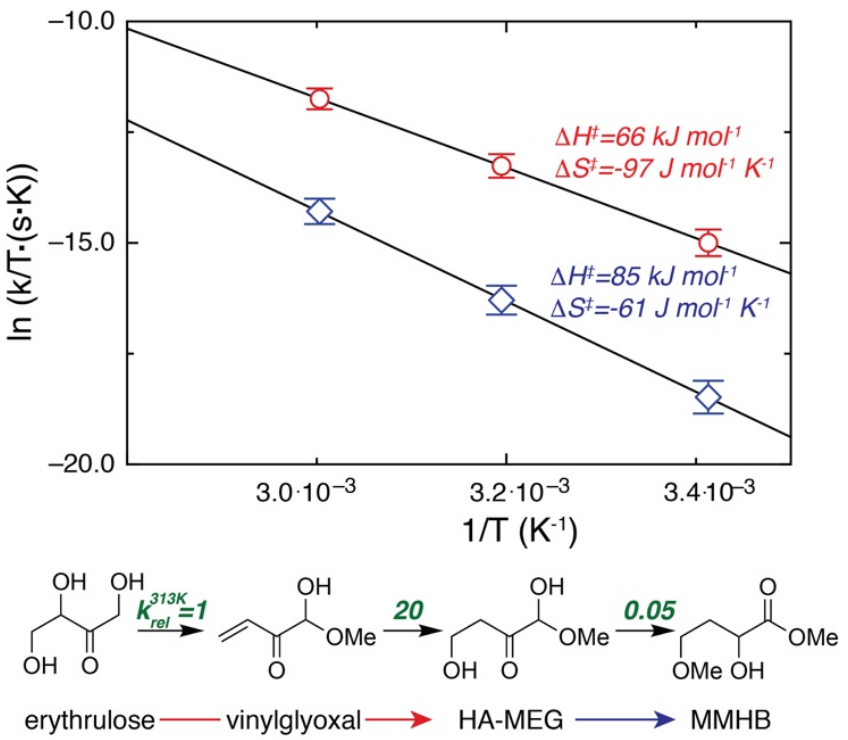

Figure 5. Eyring plots for the reaction progress kinetic analysis of erythrulose conversion by $\mathrm{SnCl}_{4} \cdot 5 \mathrm{H}_{2} \mathrm{O}$ as displayed in Figure 4 . Relative experimental reaction rates for distinguishable steps at $313 \mathrm{~K}$ are displayed for comparison.

Isotope labeling studies and quantitative NMR indicate that the substrate is the major source of labile protons

Having identified the main intermediates and visualized their fast and slow conversion in situ, we strived to gain insight into kinetic isotope effects, the reversibility of pathway steps and the stereochemistry of the intramolecular redox reactions through isotope incorporation studies.

Previous low-field NMR analysis of the conversion of erythrulose in deuterated methanol (methanol- $\mathrm{d}_{4}$ ) had detected the formation of only one MMHB product species, singly deuterated at C3. ${ }^{[1 \mathrm{~b}]}$ The presence of only one NMR-detectable species would be surprising considering that such a compound should be diastereomeric due to asymmetric mass distribution at C3 next to a chiral C2 site. In addition, analogous pathways to methyl lactate had indicated the ability to introduce more than one solvent hydrogen at C3 due to the reversibility of intermediate enolization/ketonization steps. ${ }^{[18]}$ Also, surprisingly high amounts of products protonated at $\mathrm{C} 3$ in deuterated solvent ${ }^{[1 \mathrm{~b}]}$ could raise the question of possible isotope effects in the ketonization of the C2 position.

The amounts of protonated and deuterated product were determined herein using quantitative ${ }^{13} \mathrm{C}$ NMR spectroscopy of product mixtures obtained in methanol- $\mathrm{d}_{4}$ with more than $99.8 \%$ nominal degree of deuteration. NMR spectroscopy on the reaction mixture indicated that the majority of labile protons that are incorporated during the acyclic pathway neither arise from spurious water nor from lower-than-nominal deuteration of the solvent, but from the substrate and catalyst hydroxyl groups themselves. Nevertheless, protonation of the reaction products was at least double of what was expected from the fraction of labile protons introduced by the substrate relative to the deuterated solvent. Figure 6 shows the formation of protonated and single deuterated HA-MEG intermediate that is converted to 
minor amounts of the dimethylacetal and major amounts of MMHB. The reaction profiles indicate that the surprisingly high amounts of protonated $\mathrm{MMHB}^{[1 \mathrm{~b}]}$ can be ascribed at least in part to isotope effects that lead to a faster reaction of the protonated than the deuterated intermediate. The intermediates are converted to non-deuterated, single deuterated and double deuterated products as shown in Figure 7. Due to the asymmetric mass distribution at $\mathrm{C} 3$, the single deuterated product $\mathrm{MMHB}$ yields two different signals for the two pairs of diastereomers.

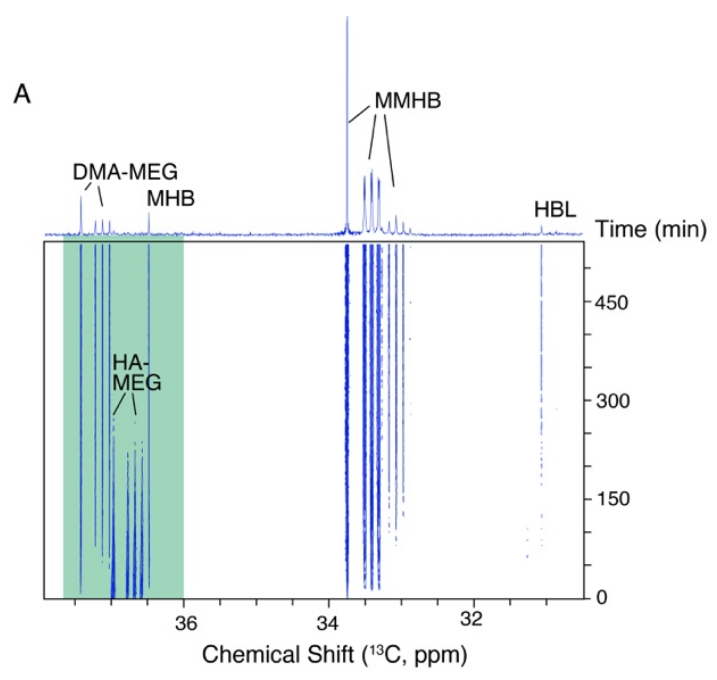

B
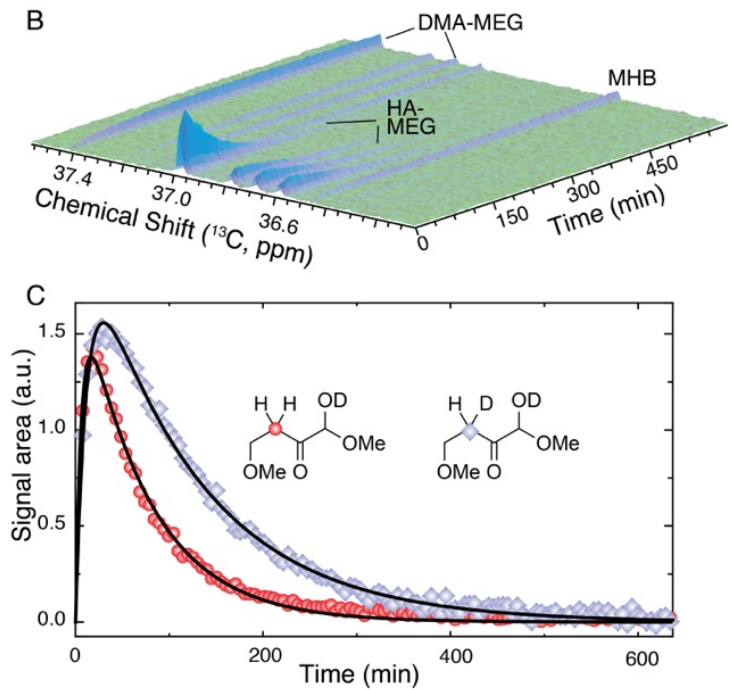

Figure 6. (A) Isotopologues formed in the conversion of protonated erythrulose in deuterated methanol as tracked in real time using a series of ${ }^{13} \mathrm{C}$ NMR spectra. (B) Zoom of the highlighted area in (A) showing that deuterated, aliphatic $\mathrm{C} 3$ positions are evident from 1:1:1 triplet signals due to coupling to the spin-1 ${ }^{2} \mathrm{H}$ nucleus. (C) Comparison of formation and conversion of C3-deuterated and C3protonated intermediate showing slower reactions of the deuterated form and fits to equations for intermediates of consecutive reactions. Reaction conditions: $50 \mathrm{mg}$ erythrulose, $20 \mathrm{mg} \mathrm{SnCl}{ }_{4} \cdot 5 \mathrm{H}_{2} \mathrm{O}, 600 \mu \mathrm{l}$ methanol- $\mathrm{d}_{4}, 323 \mathrm{~K}$.

\section{Reversibility of enolization and multiple deuteration}

Notably, we also identified the double deuterated MMHB product, in contrast to previous reports on the $\mathrm{C} 4$ system but consistent with reports of multiple deuteration at C3 in the formation of methyl lactate. ${ }^{[19]}$ This observation showed the reversible operation of enolization/ketonization steps under the catalytic conditions employed. The kinetic profiles of the different isotopologues differ noticeably, thus supporting the notion that an isotope effect in the ketonization may affect product distribution between the different isotopic forms (Figure 7).
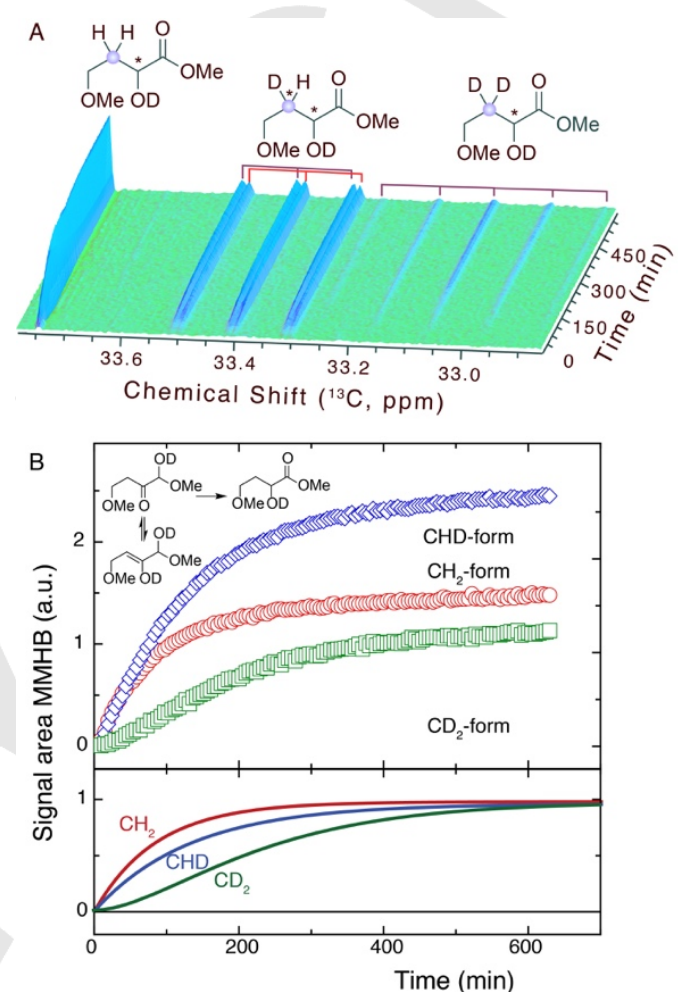

Figure 7. (A) Formation of MMHB in the experiment of Figure 6, resolving diastereomeric forms with single-deuteration at $\mathrm{C} 3$, in addition to protonated and deuterated forms. (B) Kinetic profiles of the different forms show significant differences, with the curves in the bottom representing normalized fits of the data for the three different isotopic forms to highlight the kinetic disparities.

\section{Diastereomeric deuteration indicates low stereoselectivity}

The stereoselectvitiy of the reactions converting erythrulose to MMHB were subsequently addressed. Such investigations are possible with NMR spectroscopy because enantiomeric forms become observable upon diastereomeric deuteration at the $\mathrm{C} 3$ position in the main intermediate HA-MEG and the main product $\mathrm{MMHB}$. The relative population of $\mathrm{C} 3$ protons in $\mathrm{HA}-\mathrm{MEG}$ and its dimethylacetal as well as MMHB can be visualized using ${ }^{1} \mathrm{H}-{ }^{13} \mathrm{C}$ HSQC spectra of the respective spectral regions for these $\mathrm{CH}$ groups (Figure 8). The $\mathrm{C} 3$ protons in the dimethylacetal are enantiotopic (as $\mathrm{C} 1$ carries two identical substituents), yielding only one $\mathrm{CH}$ signal. In contrast, the HA-MEG and MMHB methylene protons are diastereotopic due to the presence of a chiral center at $\mathrm{C} 1$ and $\mathrm{C} 2$, respectively. 
Both in HA-MEG and MMHB, the two triplets of the CHD group signals indicated similar propensities of deuterium to enter either of the two methylene group positions. The diastereomeric excess as determined from the HSQC integrals was less than $2.3 \%$ both for HA-MEG and MMHB, while values above $45 \%$ have been found for the $\mathrm{C} 3$ positions in $\mathrm{C} 5$ carbohydrates converted by heterogeneous Sn-containing zeolite. ${ }^{[19]}$ The lack of stereoselectivity in the formation of MMHB, indicated that both the ketonization of $\mathrm{C} 2$ and the hydride shift converting HA-MEG to MMHB have little stereoselectivity. This finding contrasted the significant stereoselectivty in larger sugars, ${ }^{[1 \mathrm{~d}, 10,19]}$ where higher populations of cyclic intermediates may affect the stereochemistry of the aforementioned reactions due to different reactivities of axial and equatorial hydrogen atoms. ${ }^{[20]}$

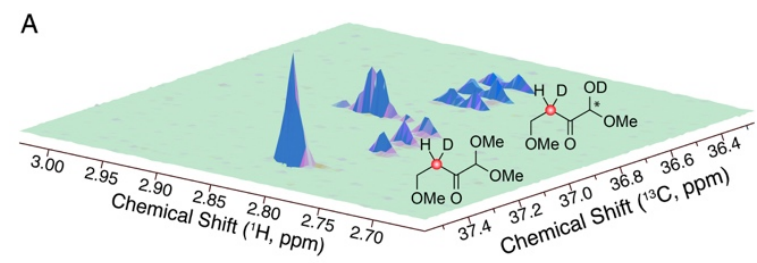

B

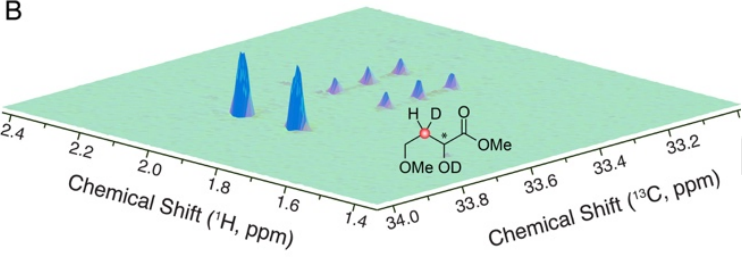

Figure 8. Methylene groups at the $\mathrm{C} 3$ position when converting erythrulose in deuterated methanol. HA-MEG and MMHB are diastereomers upon single deuteration at $\mathrm{C} 3$, yielding non-equivalent sites in the methylene group. Stereoselectivity for deuterium incorporation at the nonequivalent sites is marginal.

Finally, we observed that the propensity to incorporate deuterium at methylene C3 positions differs measurably in different pathways. Thus, $\mathrm{HBL}$ and its open chain equilibrium form MHB (Scheme 3) are not observed to carry significant deuterium incorporation at the C3-position, while MEG in its hemiacetal and dimethyl forms was found to carry one, but rarely two deuterium atoms at the $\mathrm{C} 3$ position upon reactions in deuterated methanol. This finding is consistent with the incorporation of one deuterium atom at C3 in the Michael addition of deuterated methanol to vinylglyoxal intermediate. MMHB was found to incorporate significant amounts of more than one deuterium atom at the $C 3$ position, presumably through reversible enolization of the HAMEG (and related forms such as pyruvaldehyde) ${ }^{[19]}$ intermediates in catalyst bound forms in parallel to product formation (Figure 7B, inset). As a consequence, a differential propensity for the incorporation of deuterium at the $\mathrm{C} 3$ position is found in various steps (Figure S6). These steps include reactions such as the conversion of HA-MEG to MMHB that does not require enolization, but rather is susceptible to competing enolization of the substrate. The observation of deuterium exchange at the $\alpha$-position adjacent to a keto group is consistent with reported of H/D exchange through $\alpha$-proton abstraction by heterogeneous Lewis acidic catalyst. ${ }^{[21]}$ Varying isotope effects in the respective ketonization reactions may provide a probe for the detailed understanding of the activated complexes in the respective pathways. ${ }^{[22]}$

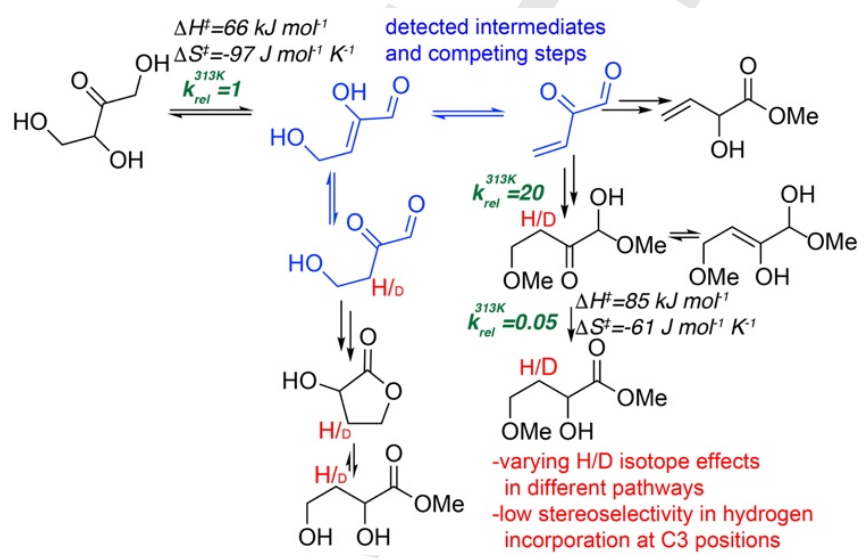

Scheme 4. Summary of findings reported herein from in situ NMR observations of Lewis acid catalyzed erythrulose conversion in methanol. Previously postulated intermediates vinylglyoxal and 3-deoxythreosone were identified and are displayed in blue, alongside competing steps for their formation. Enthalpies and entropies of activation were determined for the two rate-determining steps (black) and kinetic rates for three steps (green) along the main reaction pathway. Varying isotope effects, reversible reactions and different forms with asymmetric mass distribution were observed in competing pathways from $H / D$ exchange experiments detected by in situ NMR (red).

\section{Conclusion}

In conclusion, we find that the acyclic pathway of carbohydrate can be probed in mechanistic and kinetic detail using hyperpolarized NMR methods, in situ NMR at high magnetic field and isotope tracking methods. These approaches give fundamental insight into the initial reaction steps, pathway bottlenecks, byproducts and stereochemistry as well as mechanistic differences in the product forming reactions (Scheme 4). Detailed kinetic and mechanistic studies of $\mathrm{C} 4$ products are warranted, as C4 products are accessible not only from C4 carbohydrates, but also from smaller ${ }^{[10,11 \mathrm{~b}, 13 \mathrm{a}]}$ and $\operatorname{larger}^{[12,13 \mathrm{~b}]}$ carbohydrates. Competing formation of a 3-deoxyglycosone and vinyl glyoxal species from a transient undetected enol species is the first observable step under the current reaction conditions in methanol as the solvent. Hydrogen incorporation and hydrogen/deuterium isotope effects differ in the pathways following the competing reactions. Two predominant energetic barriers with activation enthalpies of activation of 66 and 85 $\mathrm{kJ} / \mathrm{mol}$ as well as entropies of activation of -97 and $-61 \mathrm{~J} /(\mathrm{mol} \cdot \mathrm{K})$ are found in the pathway from erythrulose to the main product MMHB. Despite of the presence of only one chiral carbon atom in the main intermediate HA-MEG (at $\mathrm{C} 1$ ) and the main product MMHB (at C2), diastereomeric forms due to asymmetric mass distributions at $\mathrm{C} 3$ in deuterated solvent reveal that ketonization reactions and final Cannizzaro-type reaction proceed with low stereoselectivity of less than $2.3 \%$ diastereomeric excess. 


\section{Experimental Section}

$\mathrm{SnCl}_{4} \cdot 5 \mathrm{H}_{2} \mathrm{O}$, erythrulose and methanol- $\mathrm{d}_{4}$ were purchased from Sigma Aldrich (St. Louis, MO, USA). Substrate and catalyst were separately dissolved as stock solutions and were mixed on ice prior to transfer to a 5 $\mathrm{mm}$ NMR tube for in situ NMR spectroscopy. In situ ${ }^{13} \mathrm{C}$ NMR spectra were recorded on a Bruker (Fällanden, Switzerland) Avance II $800 \mathrm{MHz}$ spectrometer equipped with an 18.7 T magnet (Oxford Magnet Technology, Oxford, U.K.) and a $\mathrm{TCl} Z$-gradient CryoProbe with sample temperature equilibrated to $293 \mathrm{~K}, 313 \mathrm{~K}$ or $333 \mathrm{~K}$, respectively. Reaction progress under static NMR tube conditions without further mixing ${ }^{[23]}$ was followed by pseudo-2D spectra recording a series of ${ }^{13} \mathrm{C}$ NMR spectra employing inverse-gated decoupling, $30^{\circ}$ excitation pulses and inter-scan recycle delays of 4.7 seconds. Kinetic data of reaction progress were integrated in Bruker Topspin 3.0 and fitted to a model of sequential elementary reactions in proFit 7 (Quantum Soft, Switzerland). Reactions were slow enough at $298 \mathrm{~K}$ to conduct two-dimensional assignment spectra of the reaction mixture on an $800 \mathrm{MHz}$ spectrometer to identify reaction intermediate structures of reactions initiated at $293 \mathrm{~K}, 313 \mathrm{~K}$ or $333 \mathrm{~K}$. Identical reaction profiles and similar amounts of ${ }^{13} \mathrm{C}$ signals were used to validate the assignment of the signals to the same molecule. After the reaction, quantitative $1 \mathrm{D}{ }^{13} \mathrm{C}$ NMR spectrum using inverse-gated decoupling was acquired with a recycle delay of 80 seconds and 1024 scans. High-resolution ${ }^{1} \mathrm{H}^{13} \mathrm{C}$ HSQC spectra were used to assess the stereoselectivity of reactions ${ }^{[1 \mathrm{~d}]}$ at the $\mathrm{C} 1, \mathrm{C} 2$ and $\mathrm{C} 3$ positions of the tetrose.

Hyperpolarization of natural abundance erythrulose was performed using trityl radical OX063 (Oxford Instruments, Abingdon, UK) and trimeric gadolinium chelate of 1,3,5-tris-(N-(DO3A-acetamido)- N-methyl-4-amino2-methylphenyl)-[1,3,5]triazinane-2,4,6-trione (GE Healthcare). Samples contained $100 \mathrm{mg}$ of a self-glassing mixture of OX063 (15 mM) and gadolinium chelate $(1.5 \mathrm{mM})$ directly dissolved in erythrulose. The polarization transfer was conducted at $1.2 \mathrm{~K}$ by microwave irradiation at 93.89 GHz with $100 \mathrm{~mW}$ using a HyperSense (Oxford Instruments, England) polarizer. After 1.5 hours of polarization, the samples were dissolved with $5 \mathrm{~mL}$ heated methanol- $\mathrm{d}_{4}, 300 \mu \mathrm{l}$ of the hyperpolarized substrate were injected to a solution of $\mathrm{SnCl}_{4} \cdot 5 \mathrm{H}_{2} \mathrm{O}$ (final concentration 18 $\mathrm{mg} / \mathrm{mL}$ ) in methanol- $\mathrm{d}_{4}$ placed inside a $400 \mathrm{MHz}$ Varian spectrometer. An array of 128 experiments of 1 second each was started with a nominal flip angle of $10^{\circ}$. Data were integrated in Bruker Topspin 3.0 and a non-linear least squares fit was performed in MATLAB to obtain two reaction rates $k_{1}$ and $k_{2}$ as well as the decay constants of substrate, intermediate and product hyperpolarization (23, 37 and 39 seconds, respectively, consistent with declining proton density near $\mathrm{C2}$ ). On a separate sample the polarization level was determined to $24 \%$ by comparison to a reference NMR spectrum with same pulse and acquisition parameters as for the hyperpolarized sample after addition of $10 \mu \mathrm{l}$ of $0.5 \mathrm{M}$ commercial Gdcomplex (Omniscan, GE Healthcare). $\mathrm{T}_{1}$ of the $\mathrm{C} 2$ position in erythrulose was determined to $25 \mathrm{~s}$

\section{Acknowledgements}

This work was funded by the Innovation Fund Denmark (case number 5150-00023B) and the Danish National Research Foundation (DNRF124). $800 \mathrm{MHz}$ NMR spectra were recorded on the spectrometer of the DTU NMR center supported by the Villum foundation.

Keywords: biomass $\cdot$ kinetics $\cdot$ Lewis acid $\cdot N M R \cdot$ reaction pathway
[1] a) G. R. Akien, L. Qi, I. T. Horvath, ChemComm 2012, 48, 5850-5852; b) M. Dusselier, P. Van Wouwe, F. de Clippel, J. Dijkmans, D. W. Gammon, B. F. Sels, ChemCatChem 2013, 5, 569-575; c) H. Kimura, M. Nakahara, N. Matubayasi, J. Phys. Chem. A 2013, 117, 2102-2113; d) S. Saravanamurugan, A. Riisager, E. Taarning, S. Meier, ChemComm 2016, 52, 12773-12776; e) S. Saravanamurugan, A. Riisager, E. Taarning, S. Meier, ChemCatChem 2016, 8, 3107-3111; f) Y. Wang, C. M. Pedersen, Y. Qiao, T. Deng, J. Shi, X. Hou, Carbohydr. Polym. 2015, 115, 439-443; g) J. Zhang, E. Weitz, ACS Catal. 2012, 2, 1211-1218.

[2] a) J. S. Lupoi, S. Singh, R. Parthasarathi, B. A. Simmons, R. J. Henry, Renew. Sust. Energ. Rev. 2015, 49, 871-906; b) Y. Pu, S. Cao, A. J. Ragauskas, Energy Environ. Sci. 2011, 4, 3154-3166.

[3] a) T. W. M. Fan, A. N. Lane, Prog. Nucl. Mag. Res. Sp. 2016, 92-93, 1853; b) N. Hertkorn, C. Ruecker, M. Meringer, R. Gugisch, M. Frommberger, E. M. Perdue, M. Witt, P. Schmitt-Kopplin, Anal. Bioanal. Chem. 2007, 389, 1311-1327.

[4] S. Caratzoulas, M. E. Davis, R. J. Gorte, R. Gounder, R. F. Lobo, V. Nikolakis, S. I. Sandler, M. A. Snyder, M. Tsapatsis, D. G. Vlachos, J. Phys. Chem. C 2014, 118, 22815-22833.

[5] a) S. G. Elliot, C. Andersen, S. Tolborg, S. Meier, I. Sádaba, A. E. Daugaard, E. Taarning, RSC Adv. 2017, 7, 985-996; b) S. Tolborg, S. Meier, I. Sádaba, S. G. Elliot, S. K. Kristensen, S. Saravanamurugan, A. Riisager, P. Fristrup, T. Skrydstrup, E. Taarning, Green Chem. 2016, 18, 3360-3369; c) H. Jadhav, C. M. Pedersen, T. Solling, M. Bols, ChemSusChem 2011, 4, 1049-1051.

[6] a) A. S. Amarasekara, L. D. Williams, C. C. Ebede, Carbohydr. Res. 2008, 343, 3021-3024; b) M. J. Antal Jr, T. Leesomboon, W. S. Mok, G. N. Richards, Carbohydr. Res. 1991, 217, 71-85.

[7] a) M. S. Holm, S. Saravanamurugan, E. Taarning, Science 2010, 328, 602; b) S. Tolborg, I. Sádaba, C. M. Osmundsen, P. Fristrup, M. S. Holm, E. Taarning, ChemSusChem 2015, 8, 613-617; c) M. Dusselier, P. Van Wouwe, A. Dewaele, E. Makshina, B. F. Sels, Energy Environ. Sci. 2013, 6, 1415-1442; d) L. Li, F. Shen, R. L. Smith, X. Qi, Green Chem. 2017, 19, 76-81.

[8] R. De Clercq, M. Dusselier, C. Christiaens, J. Dijkmans, R. I. lacobescu, Y. Pontikes, B. F. Sels, ACS Catal. 2015, 5, 5803-5811.

[9] a) A. Dewaele, L. Meerten, L. Verbelen, S. Eyley, W. Thielemans, P. Van Puyvelde, M. Dusselier, B. Sels, ACS Sustain. Chem. Eng. 2016, 4, 5943-5952; b) A. Sølvhøj, E. Taarning, R. Madsen, Green Chem. 2016, 18, 5448-5455.

[10] S. Tolborg, S. Meier, S. Saravanamurugan, P. Fristrup, E. Taarning, I. Sadaba, ChemSusChem 2016, 9, 3054-3061.

[11] a) S. Van de Vyver, C. Odermatt, K. Romero, T. Prasomsri, Y. RománLeshkov, ACS Catal. 2015, 5, 972-977; b) S. Yamaguchi, T. Matsuo, K. Motokura, Y. Sakamoto, A. Miyaji, T. Baba, ChemSusChem 2015, 8, 853-860.

[12] S. Lin, X. Guo, K. Qin, L. Feng, Y. Zhang, Y. Tang, ChemCatChem 2017, 9, 4179-4184.

[13] a) M. Dusselier, P. Van Wouwe, S. De Smet, R. De Clercq, L. Verbelen, P. Van Puyvelde, F. E. Du Prez, B. F. Sels, ACS Catal. 2013, 3, 17861800 ; b) M. S. Holm, Y. J. Pagán-Torres, S. Saravanamurugan, A. Riisager, J. A. Dumesic, E. Taarning, Green Chem. 2012, 14, 702-706.

[14] a) J. H. Ardenkjaer-Larsen, B. Fridlund, A. Gram, G. Hansson, L. Hansson, M. H. Lerche, R. Servin, M. Thaning, K. Golman, Proc. Natl. Acad. Sci. U.S.A. 2003, 100, 10158-10163; b) S. Meier, M. Karlsson, P. R. Jensen, ACS Sustain. Chem. Eng. 2017, 5, 5571-5577; c) S. Meier, M. Karlsson, P. R. Jensen, M. H. Lerche, J. O. Duus, Mol. Biosyst. 2011, 7, 2834-2836.

[15] K. R. Enslow, A. T. Bell, Catalysis Science \& Technology 2015, 5, 28392847.

[16] A. S. Serianni, R. Barker, J. Org. Chem. 1984, 49, 3292-3300.

[17] S. Saravanamurugan, A. Riisager, Cat. Sci. Technol. 2014, 4, 3186-3190.

[18] I. Tosi, A. Riisager, E. Taarning, P. R. Jensen, S. Meier, Cat. Sci. Technol. 2018, 8, 2137-2145

[19] S. G. Elliot, E. Taarning, R. Madsen, S. Meier, ChemCatChem 2018, 10, 1414-1419. 
[20] E. J. Corey, R. A. Sneen, J. Am. Chem. Soc. 1956, 78, 6269-6278.

[21] J. D. Lewis, S. Van de Vyver, Y. Román-Leshkov, Angew. Chem. Int. Ed. 2015, 54, 9835-9838.

[22] T. Riley, F. A. Long, J. Am. Chem. Soc. 1962, 84, 522-526.

[23] D. A. Foley, A. L. Dunn, M. T. Zell, Magn. Reson. Chem. 2016, 54, 451456. 
Entry for the Table of Contents (Please choose one layout)

Layout 1:

\section{RESEARCH ARTICLE}

Elusive intermediates and reactions can be visualized by examining the acyclic pathways of carbohydrate conversion with erythrulose substrate and in situ NMR detection.

Layout 2:

\section{RESEARCH ARTICLE}

Pernille Rose Jensen, Esben Taarning, Sebastian Meier*

Page No. - Page No.

Probing the Lewis Acid Catalyzed Acyclic Pathway of Carbohydrate Conversion in Methanol by In Situ NMR
((Insert TOC Graphic here))
Author(s), Corresponding Author(s)*

Page No. - Page No.

Title 
